\title{
Micromechanical experiments using a new inter-granule loading apparatus on gravel to ballast-sized materials
}

\author{
Chitta Sai SANDEEP, Kostas SENETAKIS* \\ City University of Hong Kong, Hong Kong SAR, China \\ Received: 02 August 2017 / Revised: 09 February 2018 / Accepted: 27 August 2018 \\ (C) The author(s) 2018. This article is published with open access at Springerlink.com
}

\begin{abstract}
Micromechanical and tribological studies of geological materials with a particular focus on their contact-mechanics behavior at the grain scale are currently a major interest in the engineering and geoscience disciplines. In this study, a new robust micromechanical apparatus developed at the City University of Hong Kong is described; it is capable of conducting inter-granule (or inter-particle) loading tests on fine gravel to ballast-sized materials of sizes as small as $5-10 \mathrm{~mm}$ to granules (or ballast) as big as $50 \mathrm{~mm}$. The focus of our study is the description of the major technical features of the new apparatus and its performance and repeatability in conducting experiments on reference grains of chrome steel balls and glass balls; in addition, we conducted a preliminary set of experiments on crushed granitic rock, which is a material widely used in geotechnical and transportation infrastructure. The representative results of these experiments are presented in terms of the normal force-displacement relationship, friction, and tangential stiffness. The newly developed large-size apparatus is further compared with a well-established apparatus that can conduct micromechanical tests on sand-sized materials.
\end{abstract}

Keywords: experimental micromechanics; contact mechanics; linear bearings; inter-particle friction; granite; debris flow; ballast

\section{Introduction}

Studies on the tribological and contact-mechanics properties of interfaces are of major theoretical and applied interest in industrial tribological applications $[1,2]$ as well as in geoscience/geotechnical engineering research and practice $[3,4]$. In recent years, there has been a rapid increase in laboratory testing to better understand the tribological behavior of geological materials at the grain scale through measurements of real soil grain response. Such studies can lead to invaluable data as well as realistic contact-mechanics models for use in computer simulations, such as the discrete element method (DEM, introduced by Cundall and Strack [5]), of powders and grains, ballast and debris flows. In DEM analysis, which is a powerful tool to study geological materials, important input parameters include the inter-particle coefficient of friction, the normal and tangential stiffness values, and their relationship with the normal load and normal/ tangential displacements.

Notable progress has been achieved in the recent past on the development of contact-mechanics models for application in geotechnical engineering and other fields as well, for example, petroleum and mining engineering or the discrete simulation of powders [4, 6-11]. However, progress in terms of experimental studies and proper equipment development, which could allow the measurement of tribological and contact-mechanics properties of natural materials at the grain scale, has been relatively slow. Analyzing the contact-mechanics behavior of natural materials which follow the sphere-sphere configuration with a good approximation is of particular interest in the

* Corresponding author: Kostas SENETAKIS, E-mail: ksenetak@cityu.edu.hk 
geotechnical, geological, and petroleum engineering disciplines. It is more difficult to simulate this type of contact in the laboratory in comparison to the more straightforward configuration of block-block type of contact with the latter being well developed and studied in the field of rock mechanics [12].

In geomechanics micromechanical research, interest in the tribological behavior of sand grains dates back to the 1960s when Horn and Deere conducted a pioneering study [13]. They developed a laboratory apparatus that was capable of testing a set of grains over the surface of a block. This particular configuration is incapable of capturing the continuous changes occurring in the surfaces in contact during sliding, which would be expected for grains of the spheresphere type. Senetakis and Coop [12] developed a new-generation laboratory apparatus, capable of simulating the sphere-sphere type of contact in sandsized materials of 1-5 mm. They resolved issues associated with adequate apparatus stiffness and inherent friction, which could otherwise affect good quality output from the experiments. This is particularly important considering that in this type of micromechanical studies, the forces and displacements under consideration may range from about 0.5 to $10 \mathrm{~N}$ (or $20 \mathrm{~N}$ ) and $10^{-4}$ to $10^{-1} \mathrm{~mm}$, respectively. These forces and displacements are much lower in magnitude in comparison to conventional geotechnical engineering testing. Prior to the study by Senetakis and Coop [12], Cavarretta et al. $[14,15]$ developed a micromechanical apparatus for studying the frictional behavior of sand-sized grains by simulating the sphere-sphere type of contact. This particular apparatus however faced a limitation in that it could not resolve forces and displacements with high precision. As a result, the tangential stiffness could not be captured but only the inter-particle coefficient of friction was measured.

Cole et al. [16-19] developed a laboratory apparatus capable of testing geological materials to provide insights into their contact-mechanics behavior. In their recent study, Yang et al. [20] described several important aspects of the tribological behavior and surface damage of sand-sized geo-materials. The apparatus developed by Senetakis and Coop [12], with additional modifications by Nardelli [21], allowed the development of a delicate configuration for applying complicated boundary conditions and loading paths to the grains.
For example, three-dimensional experiments can be conducted on two small sand-sized grains or a continuously changing normal load can be employed during shearing at the contact area of the grains, which capabilities are perhaps not easy to simulate in the devices developed by other scholars.

While studying geotechnical and geological engineering problems, it may be necessary to examine a broad range of grain sizes (or granules as referred to here). For example, in debris flow and landslide applications, Crosta et al. [22] studied six circumstances of landslides from Val Pola in the Alps and showed that the grain sizes range from 0.01 to $100 \mathrm{~mm}$ with $90 \%$ of the particles being finer than $50 \mathrm{~mm}$. Recently, due to major problems related to landslides, urgent analytical and laboratory research is being conducted to explore their fundamental behavior with micromechanicalbased approaches [23-32]. In railway and transportation engineering, large-size granules (ballast) should be simulated experimentally and numerically [33]. This is very important considering that natural grains, especially of relatively large sizes, might be of a multimineral composition and their contact area may be much greater in comparison to very small sand-sized grains.

In this study, a new micromechanical apparatus designed and constructed at the City University of Hong Kong is described. It is capable of testing granules of a wide range of sizes, thus allowing the research and study of contact-mechanics problems of a broad range of geological materials. This new apparatus has a delicate design similar to [12, 21], but has extended capabilities in the study of geomaterials, particularly for soil and rock-mechanics applications (i.e., testing fine gravel-sized relatively spherical grains to ballast, debris flow large-size materials, and rock blocks). The particular focus of this article is the description of the basic features of the newly developed (so called large-size) apparatus and a comparison of the micromechanical results obtained using this system and those obtained using an existing apparatus at the City University, which is referred to here as a small-size apparatus. Preliminary micromechanical experiments were also conducted on granules from a crushed granitic rock, which is a typical geomaterial in Hong Kong with many applications in geotechnical and transportation engineering. 


\section{The newly developed large-size inter- granule micromechanical loading apparatus}

The new apparatus described in the study was designed and constructed at the Soil Mechanics Laboratory of the City University of Hong Kong. The basic motivation behind developing this apparatus is the study of geo-materials, with major applications in landslides and debris-flow micromechanical research, which is of particular relevance to Hong Kong and also internationally. This apparatus follows the major concepts of an existing apparatus at the City University designed by Senetakis and Coop [12], which was recently modified by Nardelli [21]. An image of the newly developed apparatus is shown in Fig. 1 and a close view of the apparatus during an experimental run is included in Fig. 2. It consists of three systems, two in the horizontal direction, which are perpendicular to each other, and one in the vertical direction. Each system is composed of a linear micro-stepping motor, a non-contact eddy current displacement sensor, a load cell, and stiff mechanical parts. The two horizontal systems are used to conduct shearing tests between two granules, which can be fine gravel of about $5 \mathrm{~mm}$ or much larger grains of ballast size ( 30 to $50 \mathrm{~mm}$ in size). In reality, one horizontal system is used to conduct shearing and the second maintains the compliance of the experiment in the out-of-plane direction, even though the two horizontal systems can be used for the simultaneous shearing of more complicated loading paths. The vertical system is used to apply a constant normal force to the granules in contact during shearing and the study of the normal contact behavior of geological materials (i.e. normal forcedisplacement relationship and normal stiffness). A massive stiff frame is used for the fixity of the vertical system and the two horizontal systems are connected through linear bearings, which produce minimum friction, to a sled. The sled is the central part of the apparatus where the two grains are fixed through a system of massive mounts and wells. Note that even though the apparatus design allows the study of interfaces of geo-materials in terms of the spheresphere configuration, tests on sphere-block and blockblock types are also allowed; thus, the capabilities

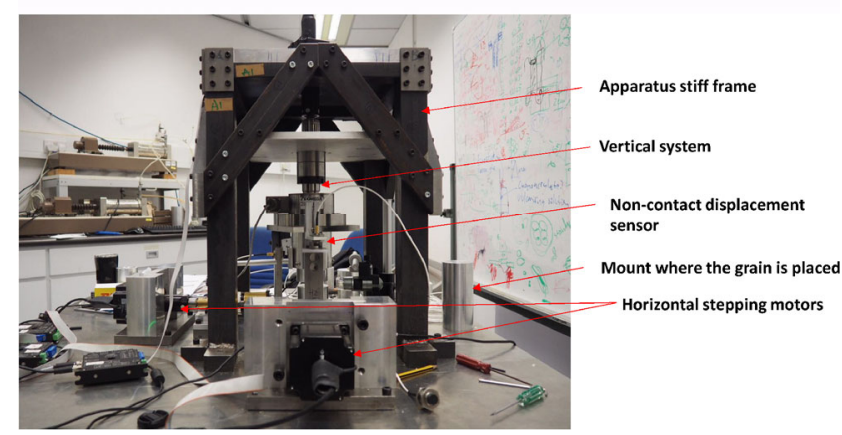

Fig. 1 The new large-size micromechanical inter-granule loading apparatus at City University of Hong Kong (frame width equal to $40 \mathrm{~cm})$.

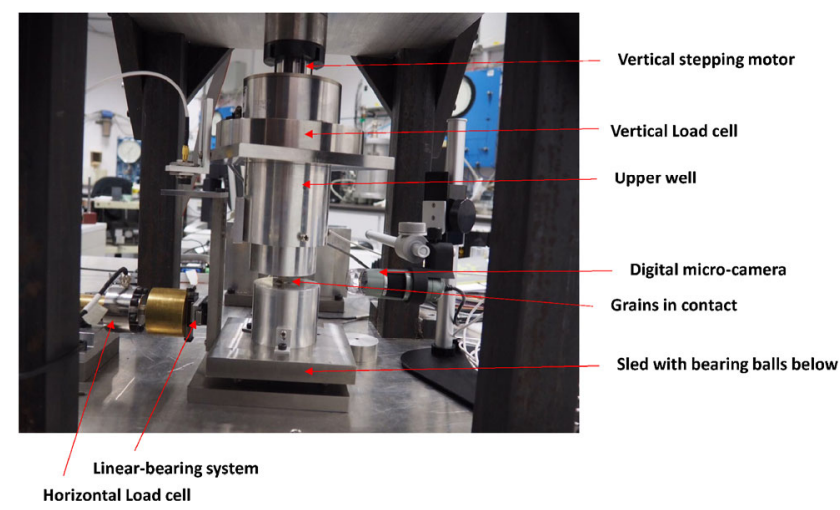

Fig. 2 A close view of the new large-size micromechanical intergranule loading apparatus at City University of Hong Kong during an experiment.

of the apparatus extend from soil mechanics to rock mechanics.

An image of the existing (small-size) apparatus [12, 21] is included in Fig. 3; it was used to validate the output of the results obtained using the new large-size apparatus on reference grains. The major differences between the two apparatus are as follows: (i) The vertical system in the newly built apparatus consists of a massive frame $(57 \mathrm{~cm} \times 40 \mathrm{~cm} \times 40 \mathrm{~cm})$ where the linear stepping motor is mounted. It is held in position by a ball spline and a $1.3 \mathrm{~cm}$-thick plate, which makes the system stiff and allows no deflection in the vertical system even at high normal loads. On the other hand, the small-size apparatus (frame size of $20 \mathrm{~cm} \times 10 \mathrm{~cm} \times 10 \mathrm{~cm}$ ) has a simpler configuration for the vertical system [12]. (ii) The two devices vary in the sizes of their component mechanical parts, including the frame, mechanical connections, and linear bearings. (iii) They are very similar in operation but consist of electronic components of different capacities, 


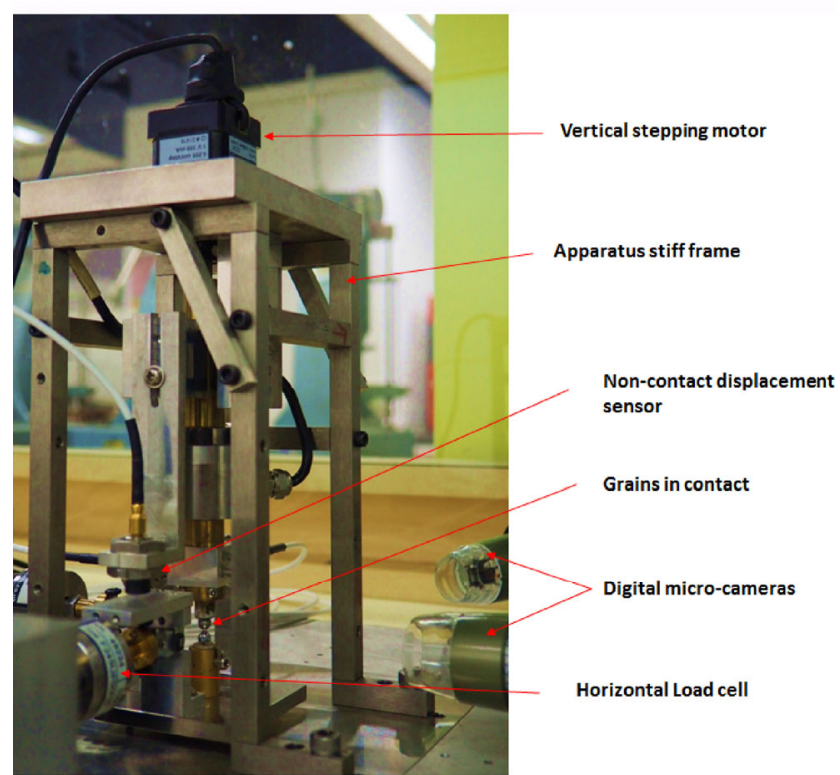

Fig. 3 The existing small-size micromechanical loading apparatus at City University of Hong Kong (frame width equal to $10 \mathrm{~cm}$ ).

for example different stepping motors and load cells of different capacities (100 $\mathrm{N}$ for the small-size apparatus and 1,000 $\mathrm{N}$ for the large-size apparatus).

Both devices are controlled by a custom-built computer code, which helps in communicating with the stepping motors, load cells and displacement sensors. Normal force through the vertical system is maintained in a force-controlled manner, while shearing is applied in a displacement-controlled manner, even though force-controlled shearing tests are also allowed, as described in another study by Senetakis et al. [34]. In addition, both devices utilize non-contact (eddy-current) displacement sensors [21] for recording or controlling tangential and normal displacements. These sensors, which are based on the employed amplifying and datalogging systems, lead to a displacement resolution of about $3 \times 10^{-4}$ to $10^{-5} \mathrm{~mm}$, making it feasible to resolve displacements at very small intervals and producing meaningful data. The output quality is enhanced using high-performance amplifying systems and data-logging systems as well as analogue filters in both devices. Currently, the newly developed large-size apparatus allows experiments to be conducted at room temperature and ambient humidity. Generally, static-type experiments can be conducted (i.e., the apparatus does not support high-frequency or very high-velocity tests), even though it allows both monotonic and cyclic (tangential or normal) static-type tests.

\section{Materials, experimental set up, and testing program}

For setting up the apparatus and conducting verification experiments, chrome steel balls of $5 \mathrm{~mm}$ diameter were used; these balls exhibited a very smooth and consistent surface [12]. Glass balls of $5 \mathrm{~mm}$ diameter were also tested in both devices. The surfaces of the glass balls are not as smooth and consistent as those of the chrome steel balls. An image of a pair of chrome steel balls during the setting up of an experiment in the large-size apparatus is shown in Fig. 4. All the tests on pairs of grains from chrome steel balls and glass balls were conducted using a normal load of $10 \mathrm{~N}$ and a sliding velocity of $0.1 \mathrm{~mm} / \mathrm{h}$.

Apart from verification tests on reference grains on both the large-size and small-size devices, an additional set of experiments was conducted on crushed granitic rock on the large-size apparatus; the granitic rock was obtained from a quarry in Mt. Butler, Hong Kong. Visual identification shows granules, which are light gray to light pink in color; further, they are equigranular with a saccharoidal-fine or a medium-grained texture. Mineralogy analysis showed that the dominant minerals are feldspar, quartz, and biotite, even though additional traces of other minerals were found in smaller percentages. The sizes of the granitic granules used in the study ranged from about 5 to $15 \mathrm{~mm}$. Morphology assessment of the grains was carried out using the Krumbein and Sloss [35] empirical chart. This method allows the quantification of the sphericity (S) and roundness (R) of a particle by visual comparison with shapes and outlines of reference projected sections of sand grains. The average sphericity and roundness of the tested granitic granules were found to be about 0.7 and 0.4 , respectively. A representative scanning

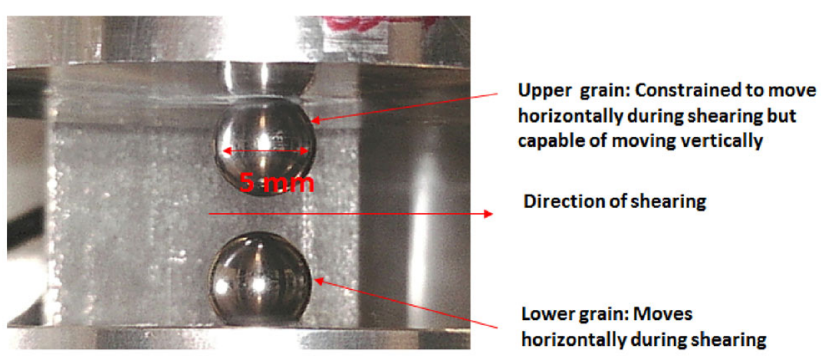

Fig. 4 Image captured by a digital microscope camera during the setting of an experiment on chrome steel balls on the large-size micromechanical apparatus. 
electron microscope (SEM) image taken from the surface of a granitic granule is included in Fig. 5; it indicates a highly rough surface for the granules. The setting up of an experiment on the large-size apparatus on crushed granitic granules is illustrated in Fig. 6. From this material, seven pairs of grains were tested under monotonic shearing paths at normal loads that ranged between $10 \mathrm{~N}$ and $30 \mathrm{~N}$. One pair of granitic granules was tested in static-cyclic mode. The interparticle sliding monotonic shearing tests conducted on chrome steel balls and glass balls are listed in Table 1. Similarly, the inter-particle sliding monotonic shearing tests conducted on granitic granules are listed in Table 2. Note that the granitic granules were tested with the same sliding velocity of $0.1 \mathrm{~mm} / \mathrm{h}$ as the reference grains. In Tables 1 and 2, each different pair of tested grains is represented with a different code

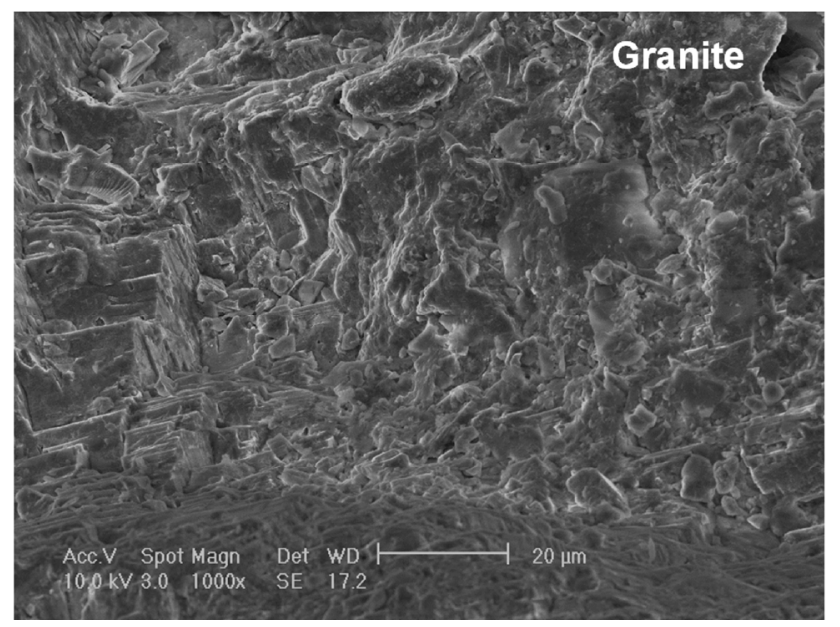

Fig. 5 SEM image of crushed granitic granules.

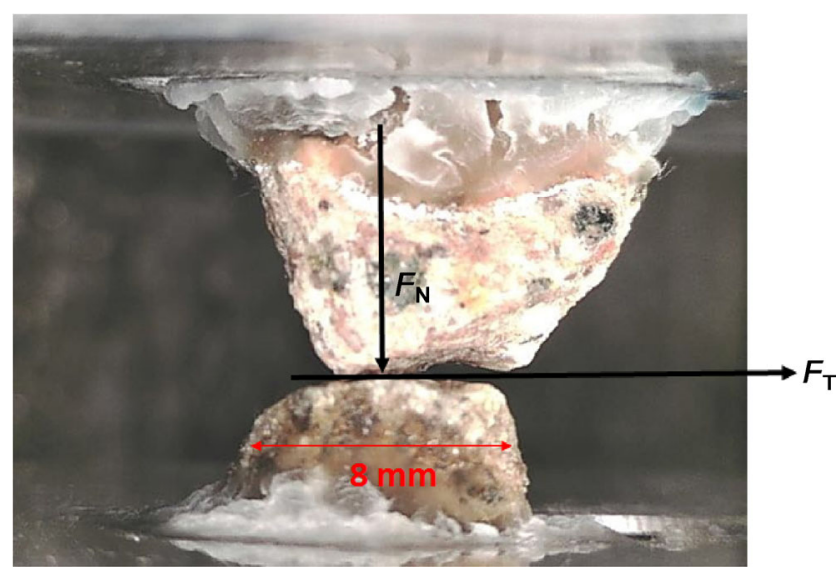

Fig. 6 Image captured by a digital microscope camera during an experiment on the large-size apparatus on crushed granitic granules $\left(F_{\mathrm{T}}\right.$ is the tangential force and $F_{\mathrm{N}}$ is the normal force). name; for example, LA-SB-1 and LA-SB-2 represent two different tests on chrome steel balls (Test No. 1 and Test No. 2), i.e., two different pairs of grains tested on the large-size apparatus. Similarly, the code SA-SB-3 corresponds to a test on pair of grains from the chrome steel balls (Test No. 8) conducted on the small-size apparatus. In total, ten pairs of grains were tested from the chrome steel balls, six pairs of grains from the glass balls, and eight pairs of grains from crushed granite (note that Table 2 shows a total of seven experimental sets on crushed granite from monotonic tests).

\section{Performance of micro-stepping motors and sensors}

A key component in the design of the new micromechanical apparatus is the minimization of environmental and electrical noise in the output from load cells and displacement sensors. Similar to the Ref. [12], this was achieved using a high-quality data logging system, amplifiers, and a filtering system. Typical plots showing the resultant noise from the load cell (in this case the load cell of the horizontal system) and the displacement sensors (vertical system) are included in Figs. 7 and 8, respectively, where the very small scatter of the output (vertical axis) is plotted against time (horizontal axis). Another key aspect behind the successful micromechanical experiments is the maintenance of the target vertical force during shearing. A typical example of this is shown in Fig. 9 in terms of the recorded normal force against tangential displacement during a shearing experiment on chrome steel balls on the large-size apparatus. Note that this is achieved not only because of the satisfactory performance of the vertical stepping motor and the high-quality output from the sensors but also because of the efficient communication between the stepping motors and sensors; such efficient communication was also observed by Senetakis and Coop [12]. Because of the relatively large size of the grains tested on the large-size apparatus, vertical loads of the order of 5 to $10 \mathrm{~N}$ are used in the micro-mechanical tests, whereas the small-size apparatus is designed to work at normal loads as small as $0.5 \mathrm{~N}$ to loads up to $\sim 10$ to $15 \mathrm{~N}$. In practice, the newly developed apparatus can conduct experiments using a shearing path of 2 to 
Table 1 Inter-particle sliding tests on chrome steel balls and glass balls.

\begin{tabular}{|c|c|c|c|c|c|c|}
\hline No. of test & Code of test & Material type & Apparatus & $\begin{array}{l}\text { Normal force, } \\
F_{\mathrm{N}}(\mathrm{N})\end{array}$ & $\begin{array}{c}\text { Tangential } \\
\text { force, } F_{\mathrm{T}}(\mathrm{N})\end{array}$ & $\begin{array}{l}\text { Inter-particle } \\
\text { coefficient of } \\
\text { friction, } \mu\end{array}$ \\
\hline 1 & LA-SB-1 & Chrome steel balls & Large-size & 10 & 0.52 & 0.05 \\
\hline 2 & LA-SB-2 & Chrome steel balls & Large-size & 10 & 0.98 & 0.10 \\
\hline 3 & LA-SB-3 & Chrome steel balls & Large-size & 10 & 0.42 & 0.04 \\
\hline 4 & LA-SB-4 & Chrome steel balls & Large-size & 10 & 1.00 & 0.10 \\
\hline 5 & LA-SB-5 & Chrome steel balls & Large-size & 10 & 0.84 & 0.08 \\
\hline 6 & SA-SB-1 & Chrome steel balls & Small-size & 10 & 0.85 & 0.09 \\
\hline 7 & SA-SB-2 & Chrome steel balls & Small-size & 10 & 0.44 & 0.04 \\
\hline 8 & SA-SB-3 & Chrome steel balls & Small-size & 10 & 0.97 & 0.10 \\
\hline 9 & SA-SB-4 & Chrome steel balls & Small-size & 10 & 0.88 & 0.09 \\
\hline 10 & SA-SB-5 & Chrome steel balls & Small-size & 10 & 0.92 & 0.09 \\
\hline 11 & LA-GB-1 & Glass balls & Large-size & 10 & 1.52 & 0.15 \\
\hline 12 & LA-GB-2 & Glass balls & Large-size & 10 & 1.80 & 0.18 \\
\hline 13 & LA-GB-3 & Glass balls & Large-size & 10 & 1.36 & 0.14 \\
\hline 14 & SA-GB-1 & Glass balls & Small-size & 10 & 1.47 & 0.15 \\
\hline 15 & SA-GB-2 & Glass balls & Small-size & 10 & 2.11 & 0.21 \\
\hline 16 & SA-GB-3 & Glass balls & Small-size & 10 & 1.20 & 0.12 \\
\hline
\end{tabular}

Note: Each code represents a different pair of grains.

Table 2 Inter-particle sliding tests on natural granite granules.

\begin{tabular}{|c|c|c|c|c|c|c|}
\hline No. of test & Code of test & Material type & Apparatus & $\begin{array}{l}\text { Normal force, } \\
\qquad F_{\mathrm{N}}(\mathrm{N})\end{array}$ & $\begin{array}{c}\text { Tangential } \\
\text { force, } F_{\mathrm{T}}(\mathrm{N})\end{array}$ & $\begin{array}{l}\text { Inter-particle } \\
\text { coefficient of } \\
\text { friction, } \mu\end{array}$ \\
\hline 1 & LA-G-1 & Crushed granite & Large-size & 10 & 2.20 & 0.22 \\
\hline 2 & LA-G-2 & Crushed granite & Large-size & 10 & 3.77 & 0.38 \\
\hline 3 & LA-G-3 & Crushed granite & Large-size & 10 & 3.23 & 0.32 \\
\hline 4 & LA-G-4 & Crushed granite & Large-size & 20 & 5.32 & 0.27 \\
\hline 5 & LA-G-5 & Crushed granite & Large-size & 30 & 8.26 & 0.28 \\
\hline 6 & LA-G-6 & Crushed granite & Large-size & 20 & 6.45 & 0.32 \\
\hline 7 & LA-G-7 & Crushed granite & Large-size & 30 & 12.82 & 0.43 \\
\hline
\end{tabular}

Note: Each code represents a different pair of grains.

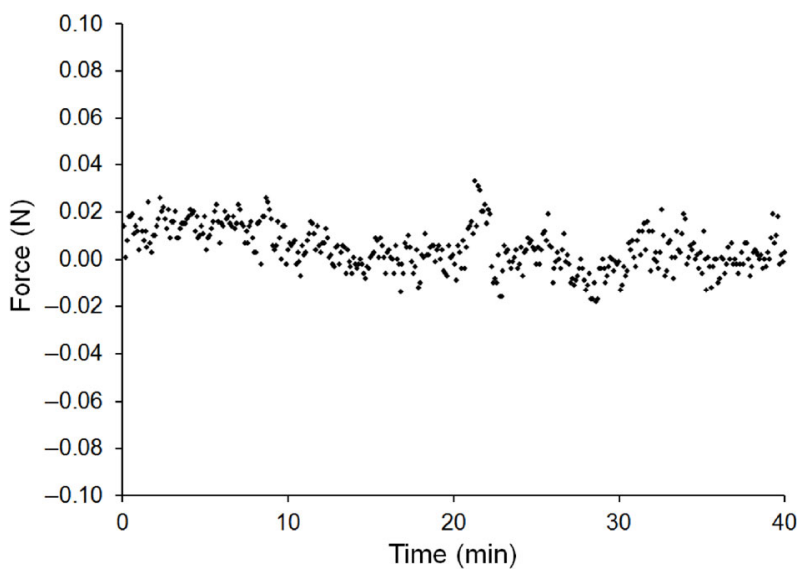

Fig. 7 Noise in the large-size apparatus. Force recorded from the load cell against time.

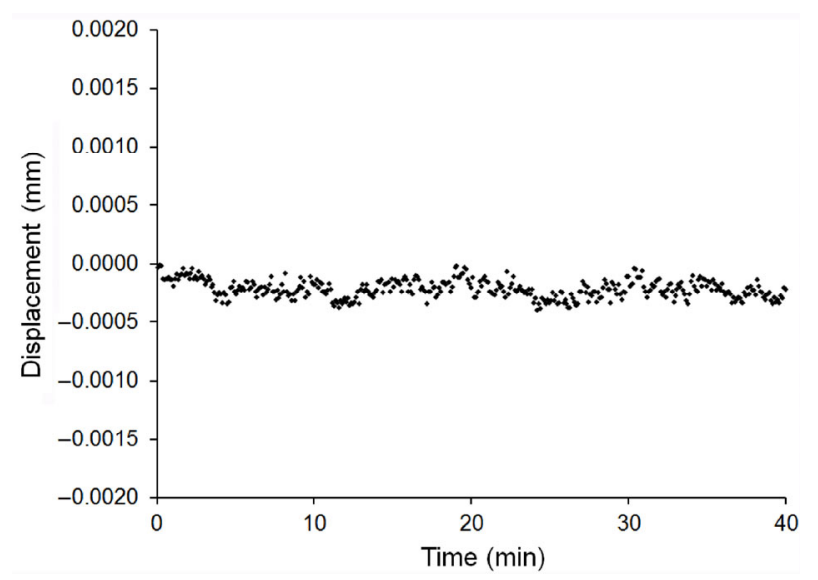

Fig. 8 Noise in the large-size apparatus. Displacement from the eddy-current sensor is recorded against time. 


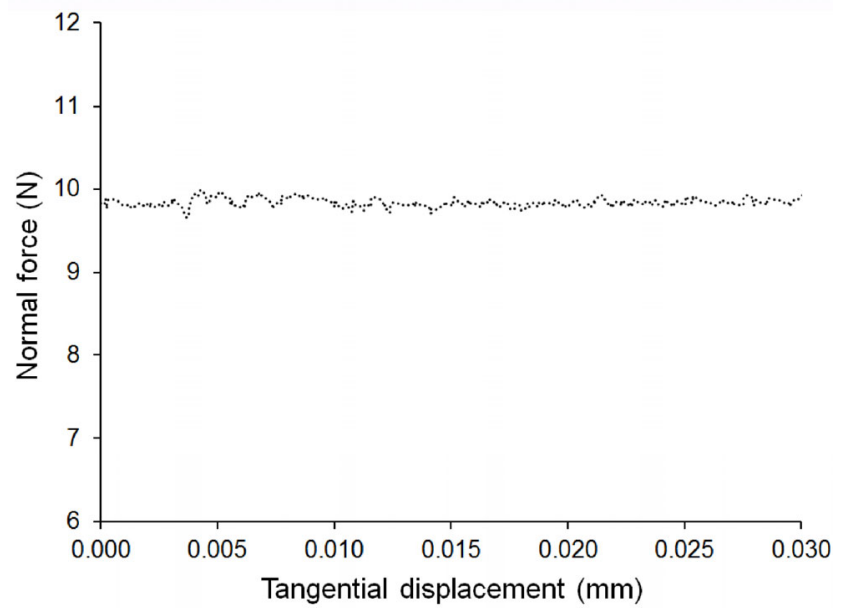

Fig. 9 Performance of the vertical micro-stepping motor in maintaining the normal force against tangential displacement during a shearing experiment on chrome steel balls.

$3 \mathrm{~mm}$ or even higher, but in this study, we limited our shearing path to a few tens of microns. This is because the testing program includes relatively smallsize granules. Thus, friction defined in this study corresponds to small shearing paths of $20-30 \mu \mathrm{m}$ for the reference grains and $\sim 60 \mu \mathrm{m}$ for the natural granules.

\section{Normal contact experiments and representative results}

Prior to shearing tests, representative plots of normal force-normal displacement during the application of a target normal load were generated. They are included in Figs. 10-12 for chrome steel balls, glass balls, and crushed granitic granules, respectively. These results are obtained on the large-size apparatus. Hertzian curves $[6,36]$ are fitted to the experimental results and the resultant apparent Young's moduli (used as the fitting parameter here) were found to be in the range of 170 to $180 \mathrm{GPa}$ and 48 to $60 \mathrm{GPa}\left(E_{1}=\right.$ $\left.E_{2}\right)$ for chrome steel balls and glass balls, respectively, which are the expected values for these material types. This also proves that the vertical system is stiff enough to yield meaningful results. This fitting was based on Eqs. (1) to (3) as follows:

$$
F_{\mathrm{N}}=\frac{4 \times\left(R^{*}\right)^{\frac{1}{2}} \times E^{*} \times \delta_{\mathrm{N}}^{\frac{3}{2}}}{3}
$$

$$
\begin{gathered}
\frac{1}{R^{*}}=\frac{1}{R_{1}}+\frac{1}{R_{2}} \\
\frac{1}{E^{*}}=\frac{1-v_{1}^{2}}{E_{1}}+\frac{1-v_{2}^{2}}{E_{2}}
\end{gathered}
$$

where $F_{\mathrm{N}}$ is the normal force, $\delta_{\mathrm{N}}$ is the normal displacement, $R^{*}$ is the equivalent radius of the grain which is computed from Eq. (2), $E^{*}$ is the equivalent (or contact) Young's modulus, and $E_{1}=E_{2}$ is the apparent modulus, which was obtained from Eq. (3). Note that for the chrome steel balls and glass balls, a Poisson ratio $\left(v_{1}=v_{2}\right)$ of 0.3 was used [37].

The corresponding Hertzian fitting for the results of crushed granitic granules was performed using the local radius of the grains in contact [38] and a Poisson's ratio value $\left(v_{1}=v_{2}\right)$ of 0.25 [39]. The contact between geological grains, which are not usually spherical in nature, is mainly non-conforming. To apply the Hertzian model to geo-materials, it is advisable to consider local radius from both directions of contact rather than considering the average radius alone. For this purpose, images during the setting up of tests on granitic granules were captured using digital microscopic cameras and their contact was analyzed from two directions. In this manner, the local radii $\left(R_{1}\right.$ and $R_{2}$ ) corresponding to the contact, were measured. The fitted curves showed that the apparent Young's modulus $\left(E_{1}=E_{2}\right)$ is within 7 to $11 \mathrm{GPa}$ for granitic granules, which is in agreement with the values reported in Ref. [40].

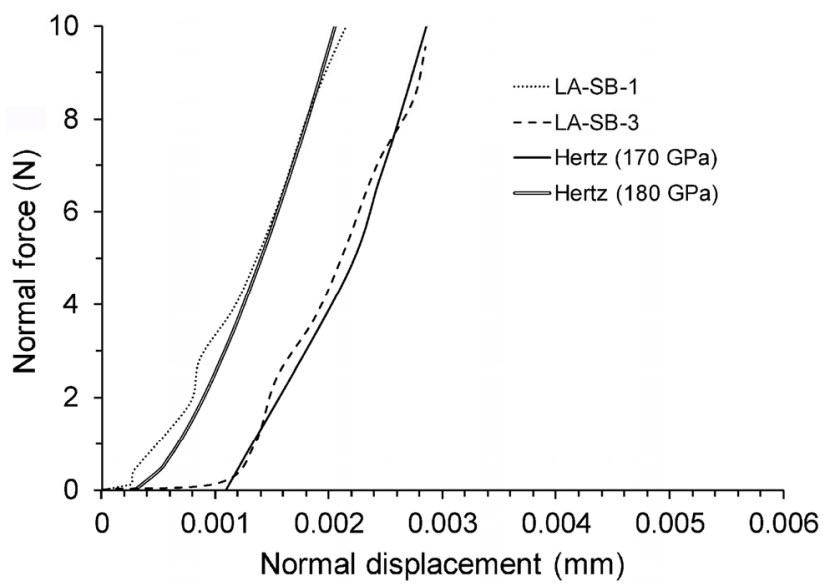

Fig. 10 Representative results of normal force against normal displacement on chrome steel balls and the corresponding Hertzian fitting. 


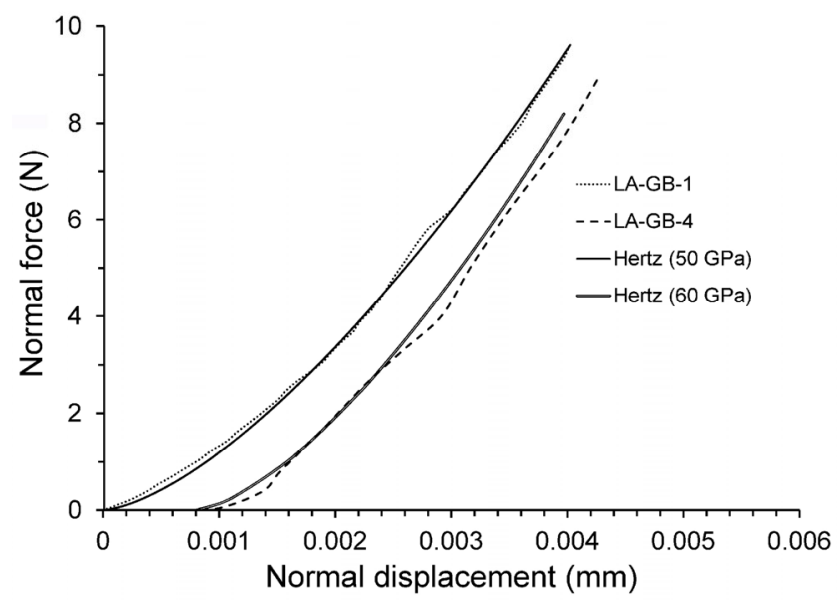

Fig. 11 Representative results of normal force against normal displacement on glass balls and the corresponding Hertzian fitting.

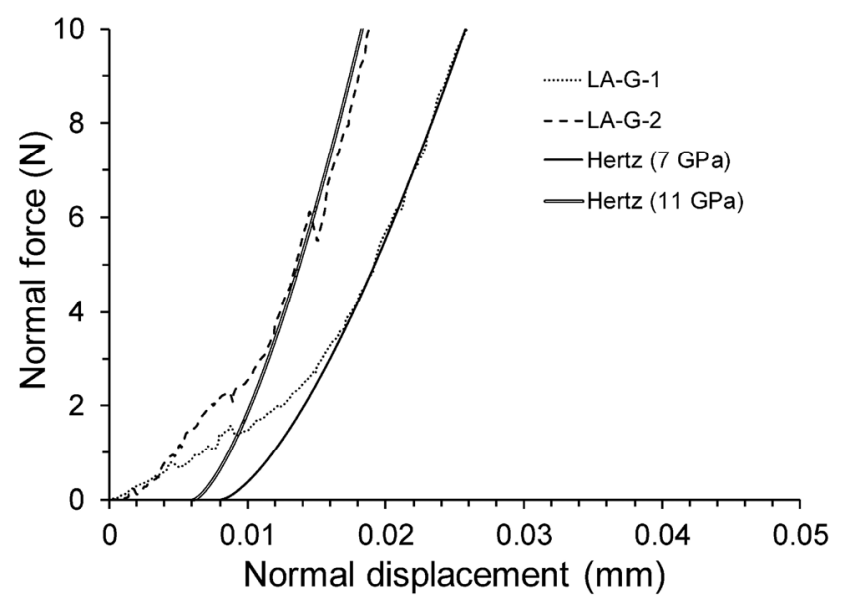

Fig. 12 Representative results of normal force against normal displacement on crushed granitic granules and the corresponding Hertzian fitting.

\section{Shearing experiments and representative results}

Representative plots of tangential (shearing) force against tangential displacement are included in Figs. 13-15 for chrome steel balls, glass balls, and crushed granitic granules, respectively. In Figs. 13 and 14, comparisons are made between the results obtained from the small-size and large-size devices for chrome steel balls and glass balls; the total set of shearing test results for the reference grains by means of tangential force at the steady-state and inter-particle coefficient of friction are summarized in Table 1 . The results corresponding to crushed granite granules tested on the large-size apparatus are summarized in Table 2.

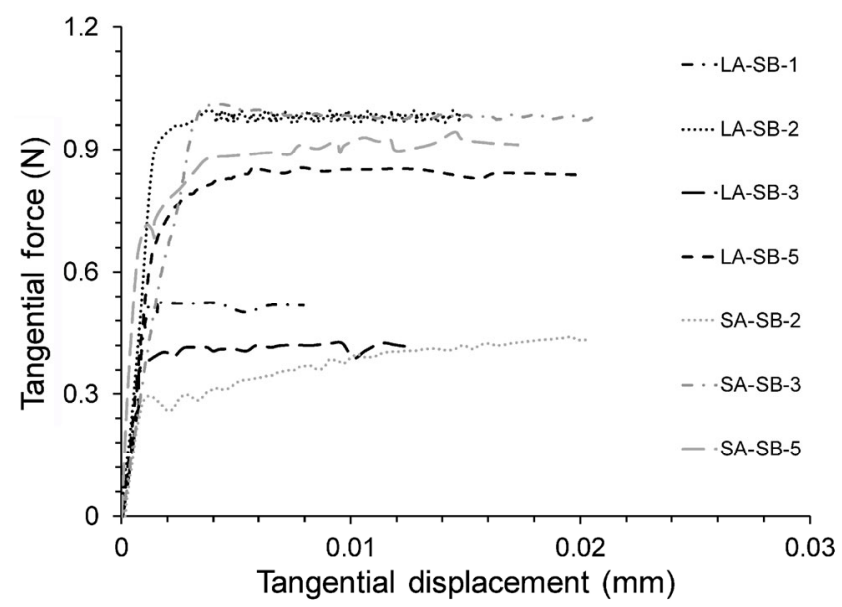

Fig. 13 Representative results of tangential force against tangential displacement at the interfaces of the chrome steel balls and a comparison between the small-size and large-size devices.

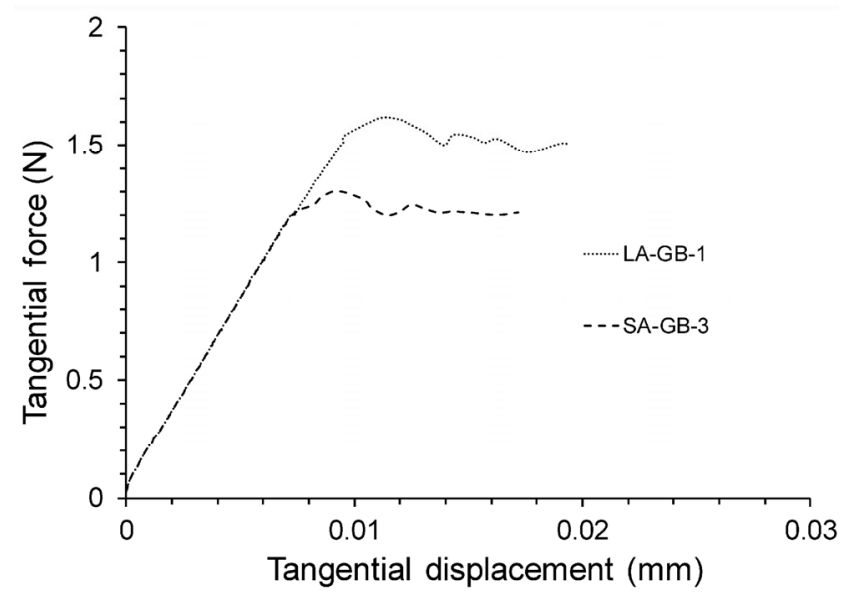

Fig. 14 Representative results of tangential force against tangential displacement at the interfaces of the glass balls and a comparison between the small-size and large-size devices.

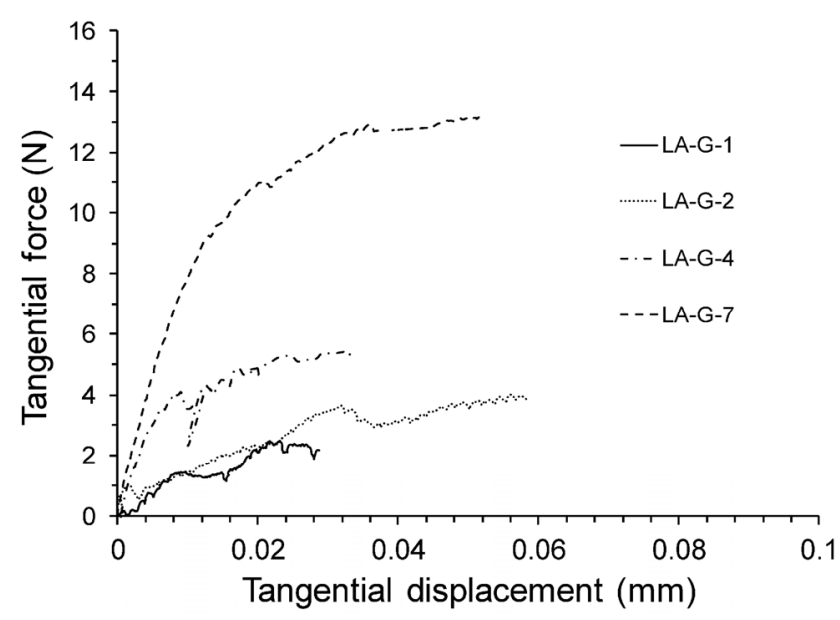

Fig. 15 Representative results of tangential force against tangential displacement at the interfaces of crushed granitic granules. 
The mobilized inter-particle coefficient of friction is calculated to be about 0.04 to 0.10 for chrome steel balls, 0.12 to 0.21 for glass balls, and 0.22 to 0.43 for the natural material (granite), respectively. A steady state is reached at tangential displacements of $\sim 1$ to $5 \mu \mathrm{m}$ for the chrome steel balls and $\sim 7$ to $10 \mu \mathrm{m}$ for the glass balls. This steady state was observed after an initial hardening regime at very small displacements for both reference materials. In the case of the natural grains, a steady state is generally reached at greater displacements, but in some of the tests, it was noticed that the tangential force fluctuated, which might be due to surface-morphology effects. In some of the experiments on crushed granite, slip behavior was more dominant than the steady state, which might probably be attributed to the effect of the asperities. This type of behavior was reported for other natural soil grains previously as well as in Ref. [38]. These differences in frictional response between different material types might be due to their different elastic properties and surface roughness [37] as well as possible effects of the material size and overall surface morphology. In the case of chrome steel balls and glass balls, there was a good agreement between the results obtained on the two devices. The friction values of the chrome steel balls, based on tests on the newly developed large-size apparatus, are very close to their counterparts obtained on the small-size apparatus as well as the results in Ref. [37]. Meanwhile, the observed friction values of the glass balls are slightly higher (average mobilized inter-particle coefficient of friction around 0.16 ) than the corresponding values obtained on smaller glass balls, as reported in Ref. [37]. Overall, these data verify the repeatability and consistency of the newly developed large-size apparatus in testing reference grains of known frictional and contact-mechanics properties. On the other hand, the results on granitic granules were more scattered, which is expected for natural geological materials, particularly considering their inconsistent and rough morphology [37, 41].

Based on the frictional test results in Figs. 13-15 and the summary of the results in Tables 1 and 2, it can be inferred that crushed granitic rock exhibits a higher inter-particle friction coefficient when compared to, for example, the corresponding values of quartz grains of Leighton Buzzard sand in Refs. [37, 38, 42], which are characterized by relatively smooth surfaces (i.e., relatively low roughness). However the friction coefficient values of crushed granitic granules are in general lower to those of very rough grains of weathered volcanic rocks and weathered granite, which were described in recent studies [37, 41, 42]. Sandeep and Senetakis [37] reported that the frictional response of geological and reference materials (of the sphere-sphere type of contact) depends on the Young's modulus of the contacting surfaces and their roughness. Therefore, it is possible that the observed differences between quartz grains, crushed granite, and weathered materials of igneous origins are because of the differences in their roughness and elastic contact properties.

Figure 16 presents representative results of tangential stiffness $\left(K_{\mathrm{T}}\right)$ as a function of the tangential displacement for chrome steel balls and granitic granules. To calculate $K_{\mathrm{T}}$, the tangential force is differentiated against displacement over a total of four to eight data points, similar to other studies [43,44]. In the case of chrome steel balls, the tangential stiffness ranged from about 400 to $600 \mathrm{~N} / \mathrm{mm}$ at displacements of about $10^{-4} \mathrm{~mm}$ (where the initial tangential stiffness $K_{\mathrm{T} 0}$ is defined in the study) and degraded to values close to zero at displacements ranging from about $2 \times 10^{-3}$ to $10^{-2} \mathrm{~mm}$. In the case of glass balls, the tangential stiffness ranged from about $300-800 \mathrm{~N} / \mathrm{mm}$ at displacements of about $10^{-4} \mathrm{~mm}$. Within the scatter of the data, there was a good agreement between the results obtained from the two devices for the reference chrome steel balls. On the other hand, in the case of the granitic granules, the value of $K_{\mathrm{T} 0}$ was found to be higher than that of reference grains, even though the initial stiffness could be defined at relatively larger displacements for natural grains (between $4 \times 10^{-4}$ to $10^{-3} \mathrm{~mm}$ ). Note the rapid drop in tangential stiffness for both materials, which indicates a highly non-linear response; these results coincide with the literature findings $[18,21,38,43,44]$ on natural materials. It is noticed however that for larger normal loads $(30 \mathrm{~N})$, in natural grains, the tangential stiffness degraded at a much slower rate than at smaller normal loads. The results of a representative static-cyclic test on a pair of crushed granitic granules are shown in Fig. 17. 


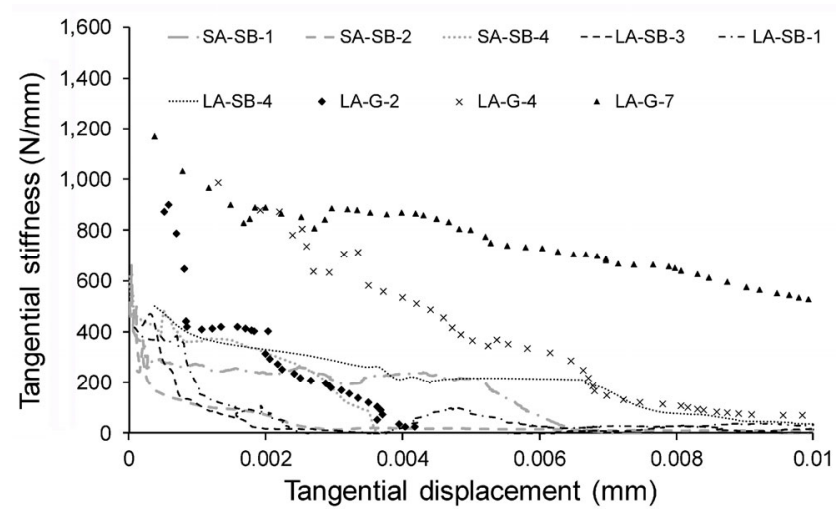

Fig. 16 Representative results of tangential stiffness against tangential displacement at the interfaces of chrome steel balls and crushed granitic granules.

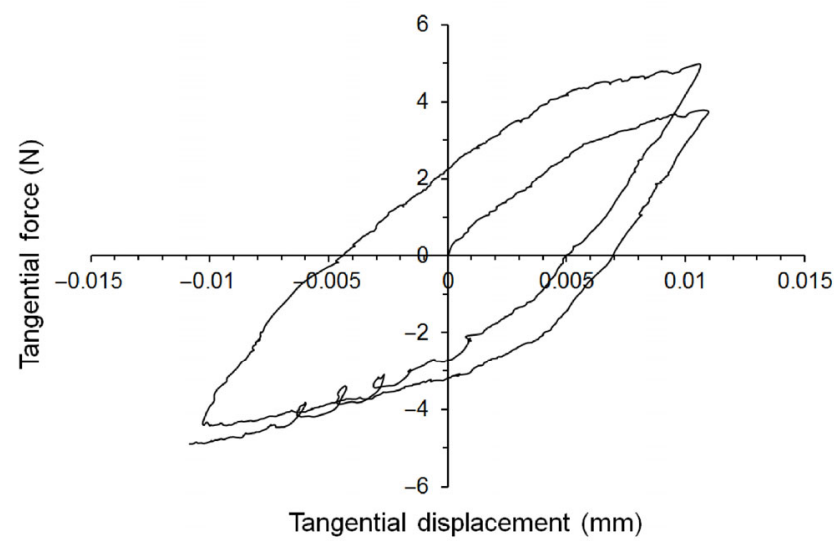

Fig. 17 A cyclic shearing test on crushed granitic granules at a normal force of $10 \mathrm{~N}$.

These data are shown only to illustrate some of the additional capabilities of the newly developed apparatus, for example in conducting cyclic tests and other complicated loading cycles. The cyclic test was conducted at a displacement amplitude of $10 \mu \mathrm{m}$ and this test resulted in a highly non-linear and hysteretic response, which is probably due to the plastic deformation of asperities, but the response was found to be very stiff during load reversal; this observation coincides with observations on other types of natural grains subjected to cyclic loading [21,38].

\section{Conclusions}

In this study, we presented the major technical features of a new micromechanical loading apparatus developed at City University of Hong Kong; the apparatus is capable of conducting tests on a broad range of materials. The necessity of simulating the sphere-sphere configuration, which leads to continuously changing contacting surfaces, at the laboratory level was highlighted. Thus, more realistic simulations of a number of natural (or man-made) processes involving powders and grains, debris flows, and other applications can be represented. The apparatus consists of three major systems, two horizontal systems perpendicular to each other and one vertical system. Micro-stepping motors, stiff mechanical parts, linear bearings, sensors, and high-quality amplifying and data-logging systems are other major features of the apparatus. Experiments on chrome steel balls and glass balls, as reference materials, were conducted and the results were compared with those obtained on an existing apparatus of similar design but of different capabilities (in terms of the grain size). The results were quite consistent between the two devices. The apparent Young's moduli calculated from normal load tests on the large-size apparatus ranged between 170-180 GPa and 48-60 GPa for chrome steel balls and glass balls, respectively. The inter-particle coefficients of friction were found to be in the range of $0.04-0.10$ and $0.12-0.21$ for the chrome steel balls and glass balls, respectively; these values are very close to previously reported data. Furthermore, a preliminary set of experiments was conducted on crushed granitic granules and a discussion was presented with respect to the friction, tangential stiffness, and normal contact response of the tested materials. Their behavior was found to be highly non-linear and hysteretic during shearing tests; Hertzian fitting yielded apparent modulus values in the range of 7 to $11 \mathrm{GPa}$ for the natural grains of crushed granite. According to the shearing test results, the inter-particle coefficient of friction ranged from 0.22 to 0.43 for the granitic granules, but it is difficult to observe a clear steady state at larger displacements. Instead, fluctuations were observed in the tangential force during tests on the granitic granules. This might be due to their micro-slip behavior and plastic deformation of the asperities. The newly developed large-size apparatus contributes to the establishment of promising research in micromechanics with a broad range of applications, from the micromechanics of debris flows to the micromechanics of ballast and other applications related to geotechnical/geological, petroleum, and mining engineering. 


\section{Acknowledgements}

The study was fully supported by a grant from the Research Grants Council of the Hong Kong Special Administrative Region, China (Theme-based research project Scheme "Understanding Debris Flow Mechanisms and Mitigating Risks for a Sustainable Hong Kong" - Project No. T22-603/15 N (CityU 8779012)). Dr. M. C. Todisco is acknowledged for her contribution during the development of the apparatus as well as Prof. M. R. Coop for his kind suggestions and discussions throughout the development of the micromechanical apparatus at City University and his invaluable contribution in the development of the computer code used with the apparatus. Mr. Thomas Tsang (technician of City University) is greatly acknowledged for his patient and continuous technical support in the development of the new micromechanical apparatus.

Open Access: The articles published in this journal are distributed under the terms of the Creative Commons Attribution 4.0 International License (http:// creativecommons.org/licenses/by/4.0/), which permits unrestricted use, distribution, and reproduction in any medium, provided you give appropriate credit to the original author(s) and the source, provide a link to the Creative Commons license, and indicate if changes were made.

\section{References}

[1] Huang P, Yang Q Q. Theory and contents of frictional mechanics. Friction 2(1): 27-39 (2014)

[2] Khan Z A, Chacko V, Nazir H. A review of friction models in interacting joints for durability design. Friction 5(1): 1-22 (2017)

[3] Soga K, O'Sullivan C. Modeling of geomaterials behavior. Soils Found 50(6): 861-875 (2010)

[4] O'Sullivan C. Particulate Discrete Element Modelling: A Geomechanics Perspective. Oxon (UK): Spon Press, 2011.

[5] Cundall P A, Strack O D L. A discrete numerical model for granular assemblies. Géotechnique 29(1): 47-65 (1979)

[6] Johnson K L. Contact Mechanics. Cambridge (UK): Cambridge University Press, 1985.

[7] Walton O R, Braun R L. Viscosity, granular-temperature, and stress calculations for shearing assemblies of inelastic, frictional disks. J Rheol 30(5): 949-980 (1986)

[8] Vu-Quoc L, Lesburg L, Zhang X. An accurate tangential force-displacement model for granular-flow simulations: Contacting spheres with plastic deformation, force-driven formulation. J Comput Phys 196(1): 298-326 (2004)

[9] Mate C M. Tribology on the Small Scale-A Bottom Up Approach to Friction, Lubrication, and Wear. Oxford (UK): Oxford University Press, 2008.

[10] Thornton C, Cummins S J, Cleary P W. An investigation of the comparative behaviour of alternative contact force models during elastic collisions. Powder Technol 210(3): 189-197 (2011)

[11] Huang X, Hanley K J, O’Sullivan C, Kwok C Y. Implementation of rotational resistance models: A critical appraisal. Particuology 34: 14-23 (2017)

[12] Senetakis K, Coop M R. The development of a new micromechanical inter-particle loading apparatus. Geotech Test J 37(6): 1028-1039 (2014)

[13] Horn H M, Deere D U. Frictional characteristics of minerals. Géotechnique 12(4): 319-335 (1962)

[14] Cavarretta I, Coop M R, O'Sullivan C. The influence of particle characteristics on the behaviour of coarse grained soils. Géotechnique 60(6): 413-423 (2010)

[15] Cavarretta I, Rocchi I, Coop M R. A new interparticle friction apparatus for granular materials. Can Geotech $J$ 48(12): 1829-1840 (2011)

[16] Cole D M, Peters J F. A physically based approach to granular media mechanics: Grain-scale experiments, initial results and implications to numerical modeling. Granul Matter 9(5): 309-321 (2007)

[17] Cole D M, Peters J F. Grain-scale mechanics of geologic materials and lunar simulants under normal loading. Granul Matter 10(3): 171-185 (2008)

[18] Cole D M, Mathisen L U, Hopkins M A, Knapp B R. Normal and sliding contact experiments on gneiss. Granul Matter 12(1): 69-86 (2010)

[19] Cole D M, Hopkins M A. The contact properties of naturally occurring geologic materials: Experimental observations. Granul Matter 18(3): 62 (2016)

[20] Yang L, Wang D G, Guo Y B, Liu S H. Tribological behaviors of quartz sand particles for hydraulic fracturing. Tribol Int 102: 485-496 (2016)

[21] Nardelli V. An experimental investigation of the micromechanical contact behaviour of soils. Ph.D Thesis. Hong Kong (China): City University of Hong Kong, 2017.

[22] Crosta G B, Frattini P, Fusi N. Fragmentation in the Val Pola rock avalanche, Italian Alps. J Geophys Res Earth Surf 112(F1): F01006 (2007) 
[23] Cleary P W, Campbell C S. Self-lubrication for Long Runout Landslides: Examination by computer simulation. J Geophys Res Solid Earth 98(B12): 21911-21924 (1993)

[24] Utili S, Zhao T, Houlsby G T. 3D DEM investigation of granular column collapse: Evaluation of debris motion and its destructive power. Eng Geol 186: 3-16 (2015)

[25] Crosta G B, Calvetti F, Imposimato S, Roddeman D, Frattini P, Agliardi F. Granular flows and numerical modelling of landslides. Report of Damocles Project EVG1-CT-199900007, 2001: 16-36

[26] Calvetti F, Nova R. Micromechanical approach to slope stability analysis. In Degradations and Instabilities in Geomaterials. Darve F, Vardoulakis I, Eds. Vienna: Springer, 2004: 235-254

[27] Zhao J D, Shan T. Coupled CFD-DEM simulation of fluid-particle interaction in geomechanics. Powder Technol 239: 248-258 (2013)

[28] Choi C E, Goodwin G R, Ng C W W, Cheung D K H, Kwan J S H, Pun W K. Coarse granular flow interaction with slit structures. Géotech Lett 6(4): 267-274 (2016)

[29] Choi C E, Au-Yeung S C H, Ng C W W, Song D. Flume investigation of landslide granular debris and water runup mechanisms. Géotech Lett 5(1): 28-32 (2015)

[30] Choi C E, Ng C W W, Song D, Kwan J S H, Shiu H Y K, Ho K K S, Koo R C H. Flume investigation of landslide debris-resisting baffles. Can Geotech $J$ 51(5): 540-533 (2014)

[31] Choi C E, Ng C W W, Au-Yeung S C H, Goodwin G. Froude scaling of landslide debris in flume modelling. Landslides 12(6): 1197-1206 (2015)

[32] Law R P H, Choi C E, Ng C W W. Discrete-element investigation of influence of granular debris flow baffles on rigid barrier impact. Can Geotech J 53(1): 179-185 (2016)

[33] Ahmed S, Harkness J, Le Pen L, Powrie W, Zervos A. Numerical modelling of railway ballast at the particle scale. Int J Numer Anal Methods Geomech 40(5): 713-737 (2016)

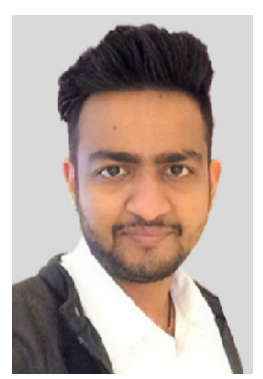

Chitta SAI SANDEEP. He received a bachelor degree in civil engineering from Jawaharlal Nehru Technological University (JNTU), Kakinada in 2013 and a master degree in geotechnical engineering from the Indian Institute of Technology (Guwahati) in 2016.
[34] Senetakis K, Coop M R, Todisco M C. The inter-particle coefficient of friction at the contacts of Leighton Buzzard sand quartz minerals. Soils Found 53(5): 746-755 (2013)

[35] Krumbein W C, Sloss L L. Stratigraphy and Sedimentation. 2nd ed. San Francisco (USA): W. H. Freeman and Company, 1963

[36] Hertz H. Uber die Beruhrung fester elastischer Korper (On the contact of elastic solids). J Reine Angew Math 92: 156-171 (1882)

[37] Sandeep C S, Senetakis K. Effect of Young's modulus and surface roughness on the inter-particle friction of granular materials. Materials 11(2): 217 (2018)

[38] Sandeep C S, Senetakis K. Grain-scale mechanics of quartz sand under normal and tangential loading. Tribol Int 117: 261-271 (2018)

[39] Jaeger J C, Cook N G W, Zimmerman R. Fundamentals of Rock Mechanics. New York (USA): John Wiley \& Sons, 2009

[40] Kitsunezaki C. In situ determination of variation of Poisson's ratio in granite accompanied by weathering effect and its significance in engineering projects. Bull Dis Prevent Res Inst 15(2): 19-41 (1965)

[41] Sandeep C S, Todisco M C, Senetakis K. Tangential contact behaviour of a weathered volcanic landslide material from Hong Kong. Soils Found 57(6): 1096-1102 (2017)

[42] Sandeep C S, Senetakis K. Exploring the micromechanical sliding behavior of typical quartz grains and completely decomposed volcanic granules subjected to repeating shearing. Energies 10(3): 370 (2017)

[43] Senetakis K, Coop M R. Micro-mechanical experimental investigation of grain-to-grain sliding stiffness of quartz minerals. Exp Mech 55(6): 1187-1190 (2015)

[44] Senetakis K, Sandeep C S, Todisco M C. Dynamic interparticle friction of crushed limestone surfaces. Tribol Int 111: $1-8$ (2017)

He worked as a site engineer during the construction of the Delhi Metro railway. Currently, he is a $\mathrm{PhD}$ student at City University of Hong Kong, working under the supervision of Dr. Kostas Senetakis. His current research focuses on contact mechanics and the tribological study of various materials, particularly debris flow soils. 


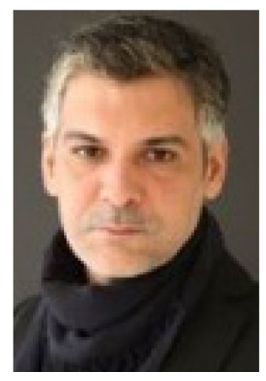

Kostas SENETAKIS. He is currently an assistant professor in the Department of Architecture and Civil Engineering at City University of Hong Kong. He holds a 5-year required Diploma in civil engineering and completed his MSc in earthquake engineering in 2006 and $\mathrm{PhD}$ in civil engineering in 2011, majoring in soil dynamics, at Aristotle University of Thessaloniki, Greece. Prior to joining City University of Hong Kong as an academic, Dr. Senetakis worked for two years as a post-doctoral research fellow at City University of Hong Kong and three years as a lecturer in
Thailand and Australia. Dr. Senetakis's research focuses include experimental soil mechanics and dynamics, experimental micromechanics and tribology of non-conforming surfaces, and geo-synthetics and recycled aggregates in geotechnics. He made key contributions to fundamental studies on the stiffness and damping of granular materials, applications of dynamic test methods in the laboratory, and micromechanical studies on grain contact response and surface damage at the nano-to-micro level. He is the in-charge academic of the Soil Mechanics Laboratory of the City University of Hong Kong, which is one of the most advanced laboratories across the world in element testing and micromechanics. 